\title{
Regulation of Neurogenesis in Adult Mouse Hippocampus by cAMP and the cAMP Response Element-Binding Protein
}

\author{
Shin Nakagawa, Ji-Eun Kim, Rena Lee, Jessica E. Malberg, Jingshan Chen, Cathy Steffen, Ya-Jun Zhang, \\ Eric J. Nestler, and Ronald S. Duman \\ Division of Molecular Psychiatry, Abraham Ribicoff Research Facilities, Connecticut Mental Health Center, Yale University \\ School of Medicine, New Haven, Connecticut 06508
}

The cAMP cascade, including the cAMP response elementbinding protein (CREB), is known to play an important role in neuronal survival and plasticity. Here the influence of this cascade on neurogenesis in adult hippocampus was determined. Activation of the cAMP cascade by administration of rolipram, an inhibitor of cAMP breakdown, increased the proliferation of newborn cells in adult mouse hippocampus. In addition, rolipram induction of cell proliferation resulted in mature granule cells that express neuronal-specific markers. Increased cell proliferation is accompanied by activation of CREB phosphor-

Neurogenesis occurs in adult brain of several different species, including human (Eriksson et al., 1998; Pincus et al., 1998; Kukekov et al., 1999), and is a dynamic process that is regulated in both a positive and negative manner by environmental, endocrine, and pharmacological stimuli. For example, enriched environment, exercise, or hippocampal-dependent models of learning increase neurogenesis in adult (Kempermann et al., 1997; Gould et al., 1999; van Praag et al., 2000). In contrast, aging, environmental, or psychosocial stress, as well as administration of adrenal glucocorticoids, decrease neurogenesis in the hippocampus (Kuhn et al., 1996; Gould et al., 1997; Cameron and McKay, 1999). Downregulation of adult neurogenesis in response to stress and high levels of adrenal glucocorticoids could contribute to the decreased volume of hippocampus that has been observed in the brains of patients with mood disorders (Sheline et al., 1996; Steffens et al., 2000). In contrast, hippocampal neurogenesis is upregulated by antidepressant treatment (Malberg et al., 2000a), and this effect could reverse or block the damaging effects of stress on hippocampus. These findings indicate that neurogenesis is a form of neural plasticity that contributes to the ability of adult hippocampus to adapt and respond to a variety of stimuli.

Although progress has been made in characterizing the neurotransmitters and trophic factors that regulate neurogenesis (Cameron et al., 1998; Gage, 2000), much less is known about the intracellular signal transduction cascades that influence this process in adult hippocampus. The cAMP signal transduction cas-

\footnotetext{
Received Oct. 5, 2001; revised Dec. 6, 2001; accepted Jan. 15, 2002.

This work is supported by United States Public Health Service Grants MH45481 and 2 PO1 MH25642 and a Veterans Administration National Center Grant for post-traumatic stress disorder.

Correspondence should be addressed to Ronald S. Duman, 34 Park Street, New Haven, CT 06508. E-mail: ronald.duman@yale.edu.

C. Steffen's and E. J. Nestler's present address: Department of Psychiatry, University of Texas Southwestern Medical Center, 5323 Harry Hines Boulevard, Dallas, TX 75390-9070.

Copyright (C) 2002 Society for Neuroscience $\quad 0270-6474 / 02 / 223673-10 \$ 15.00 / 0$
}

ylation in dentate gyrus granule cells, suggesting a role for this transcription factor. This possibility is supported by studies demonstrating that cell proliferation is decreased in conditional transgenic mice that express a dominant negative mutant of CREB in hippocampus. The results suggest that the CAMPCREB cascade could contribute to the actions of neurotransmitters and neurotrophic factors on adult neurogenesis.

Key words: rolipram; phosphodiesterase; transgenic mice; phosphorylation; proliferation; granule cell; transcription factor

cade, including the cAMP response element-binding protein (CREB), is one potential candidate. Activation of this pathway is known to increase performance in cellular and behavioral models of learning and memory and to mediate neurotrophic factorinduced cell survival (Silva et al., 1998; Finkbeiner, 2000). Studies in cultured progenitor cells demonstrate that activation of the cAMP pathway increases neuronal differentiation and neurite outgrowth (Palmer et al., 1997; Takahashi et al., 1998). In addition, antidepressant treatment upregulates the cAMP signal transduction cascade in hippocampus (Duman et al., 1997b, 2000), and this could mediate the action of antidepressants on neurogenesis (Malberg et al., 2000a).

The current study examines the influence of the cAMP system on neurogenesis in adult rodent hippocampus. The cAMP cascade can be pharmacologically regulated in vivo by administration of rolipram, an inhibitor of phosphodiesterase type IV (PDE4). PDE4 is a subfamily of high-affinity, cAMP-specific enzymes that degrade cAMP (Conti et al., 2000). In addition, the role of CREB in neurogenesis is examined. CREB is a transcription factor that is activated by its phosphorylation on $\mathrm{Ser}^{133}$ via cAMPdependent protein kinase, as well as by $\mathrm{Ca}^{2+}$ - and neurotrophic factor-dependent signaling pathways (Duman et al., 2000). We generated an inducible transgenic mouse that overexpresses a dominant negative phosphorylation mutant of CREB ( $\operatorname{Ser}^{133}$ to Ala) in the granule cell layer (GCL) of hippocampus for these studies. The results demonstrate that activation of the cAMP pathway increases the proliferation of hippocampal granule cells and that inhibition of CREB decreases this process.

\section{MATERIALS AND METHODS}

Drug treatment. Male C57BL/6 mice, 8-10 weeks old (Charles River Laboratories, Wilmington, MA), were used for the study with rolipram. For the chronic paradigm, mice were given saline containing 2\% DMSO as control or rolipram $(1.25 \mathrm{mg} / \mathrm{kg}$, i.p; Sigma, St. Louis, MO) in saline containing $2 \%$ DMSO daily for $14 \mathrm{~d}$. To evaluate the effect of rolipram on cell proliferation, bromodeoxyuridine (BrdU) $(75 \mathrm{mg} / \mathrm{kg}$, i.p; Sigma) 
was administered to label dividing cells $2 \mathrm{hr}$ after the last injection of rolipram or vehicle. Mice were killed $2 \mathrm{hr}$ (control, $n=7$; rolipram, $n=$ 8 ) or $24 \mathrm{hr}$ (control, $n=6$; rolipram, $n=6$ ) after BrdU injection. For the acute paradigm, saline $(n=5)$ or rolipram $(n=8)$ was administered once. Two hours after the injection, mice were given a single injection of BrdU once and killed $24 \mathrm{hr}$ later. To evaluate the effect of chronic rolipram on survival of newly born cells, mice were given BrdU every 2 hr three times after chronic saline $(n=7)$ or rolipram $(n=7)$ administration and killed 4 weeks after BrdU injection. All mice were given BrdU at postnatal week 10. All animal procedures were in strict accordance with the National Institutes of Health Guide for the Care and Use of Laboratory Animals and were approved by the Yale Animal Care and Use Committee.

Transgenic mice. To assess the effect of dominant negative mutants of CREB on the cell proliferation in the adult hippocampus, we generated transgenic mice expressing CREB mutant (mCREB) under the tetracycline responsive promoter (Furth et al., 1994; Chen et al., 1998). The CREB mutant contains a conservative serine to alanine substitution at position 133, which destroys the protein kinase A phosphorylation site but maintains charge balance (Gonzalez and Montminy, 1989). Although not phoshorylated, mCREB can still bind to the CRE. Thus, mCREB inhibits CREB action by occupying the CRE and preventing access by wild-type CREB and other CRE-binding factors (Shaywitz and Greenberg, 1999). The mCREB construct, a gift from Michael E. Greenberg (Harvard University, Boston, MA) was engineered with a FLAG tag peptide (Asp-Tyr-Lys-Asp-Asp-Asp-Asp-Lys) at the $\mathrm{N}$ terminus so that mCREB could be distinguished from endogenous CREB. A $1.1 \mathrm{~kb}$ fragment of the vector containing $\mathrm{MCREB}$ was released by digestion with HindIII and $X b a \mathrm{I}$ and subcloned into the pTet-splice (Shockett et al., $1995)$ in place of the TetOP minimal cytomegalovirus promoter. The new plasmid was designated as pTetOP-mCREB. DNA fragment [containing the promoter, open reading frame, SV40 intron, and poly $\left(\mathrm{A}^{+}\right)$ signal] from pTetOP-mCREB was purified by electroelution and microinjected into the pronuclei of oocytes from SJL $\times$ C57BL/6 mice. The mice expressing the tTA gene under the control of $\mathrm{Ca}^{2+}$-calmodulindependent kinase II $\alpha$ (CaMKII) promoter, CaMKII-tTA, were provided by Eric R. Kandel (Columbia University, New York, NY) (Mayford et al., 1996). Tail DNA from both mice was isolated using Tissue Amp DNA kit (Quiagen, Chatsworth, CA) and analyzed for the transgene by PCR. Of these techniques, PCR was used for routine genotyping of the transgenic mice. The CaMKII-tTA transgene was detected by PCR with the following primers: TTAB1, 24-mer, 5' GCG ACT TGA TGC TCT TGA TCT TCC 3'; and TTAF1, 24-mer, 5' GAG CTG CTT AAT GAG GTC GGA ATC 3'. The TetOP-mCREB transgene was detected by PCR with the following primers: CREB-B1, 24-mer, 5' GCT GCA TTG GTC ATG GTT AAT GTC 3'; and CREB-F1, 25-mer, 5' CAG CCA TCA GTT ATT CAG TCT CCA C 3'. The founder mice were crossbred with the ICR outbred mouse line to generate F1 mice. F2 homozygous transgenic mice were obtained by crossbreeding F1 siblings; homozygous genotype was confirmed by crossbreeding them with wildtype mice. We used only one line for each single transgenic mouse for the present study. During the prenatal period to postnatal week 6 , the transgenic mice were given doxycycline $(100 \mu \mathrm{g} / \mathrm{ml})$ (Sigma), an analog of tetracycline, in drinking water to turn off the expression of mCREB in mice carrying the CaMKII-tTA gene plus TetOP-mCREB (Chen et al., 1998). From postnatal weeks 6-10, mice were fed without doxycycline to wash out doxycycline and express the target gene. At postnatal week 10, mice (CaMKII-tTA single transgenic mice, $n=4$; TetOP-mCREB single transgenic mice, $n=7$; CaMKII-tTA $\times$ TetOP-mCREB bitransgenic mice, $n=5$ ) were given BrdU once and killed 2 hr later to evaluate the cell proliferation in the adult hippocampus. All of the transgenic mice used in this study were maintained in strict accordance with National Institutes of Health and institutional animal care guidelines.

Immunohistochemistry. All mice were killed via intracardial perfusion with $4 \%$ paraformaldehyde under anesthetization with sodium pentobarbital (100 mg/kg, i.p.). A freezing microtome was used to collect serial coronal $30 \mu \mathrm{m}$ sections through the entire hippocampus. Every sixth or ninth section was slide mounted for peroxidase BrdU immunolabeling. The sections were incubated in $0.01 \mathrm{M}$ citric acid at $90^{\circ} \mathrm{C}$, digested in trypsin $(0.1 \%)$ in Tris buffer containing $0.1 \% \mathrm{CaCl} 2$ for $10 \mathrm{~min}$, denatured in $2 \mathrm{~N} \mathrm{HCl}$ for $30 \mathrm{~min}$, blocked in $3.0 \%$ normal horse serum for 20 min, and incubated overnight at $4^{\circ} \mathrm{C}$ in mouse monoclonal antibody against BrdU (1:100; Becton Dickinson, San Jose, CA) in PBS containing $3 \%$ normal horse serum and $0.1 \%$ Tween 20 . On the next day, the sections were incubated in biotinylated mouse secondary antisera (1:200;
Vector Laboratories, Burlingame, CA) for $60 \mathrm{~min}$, incubated in avidinbiotin-horseradish peroxidase (1:50; Vector Laboratories) for $60 \mathrm{~min}$, and reacted in the solution of 3,3'-diaminobenzidine containing nickel ammonium sulfate (Vector Laboratories). The sections were counterstained with cresyl violet. For peroxidase FLAG immunolabeling, freefloating $30 \mu \mathrm{m}$ sections from transgenic mice were used. Sections were incubated in $0.5 \%$ Triton $\mathrm{X}-100$ in TBS for $45 \mathrm{~min}$ at $4^{\circ} \mathrm{C}$, blocked in $5.0 \%$ normal horse serum- $-1 \%$ Triton X-100 in TBS for 45 at $4^{\circ} \mathrm{C}$, and incubated overnight at $4^{\circ} \mathrm{C}$ in mouse monoclonal antibody against FLAG (1:1000; Sigma). The avidin-biotin blocking kit (Vector Laboratories) was used at these steps to reduce the nonspecific labeling. The following step was done as described above except for the counterstaining. For immunofluorescence staining, free-floating $30 \mu \mathrm{m}$ sections were used. The following DNA denaturation steps preceded the incubation with anti-BrdU antibody: $2 \mathrm{hr}$ incubation in $50 \%$ formamide- $2 \times$ SSC $(0.3 \mathrm{M}$ $\mathrm{NaCl}$ and $0.03 \mathrm{M}$ sodium citrate) at $65^{\circ} \mathrm{C}, 5 \mathrm{~min}$ rinse in $2 \times \mathrm{SSC}, 30 \mathrm{~min}$ incubation in $2 \mathrm{~N} \mathrm{HCl}$ at $37^{\circ} \mathrm{C}$, and $10 \mathrm{~min}$ rinse in $0.1 \mathrm{M}$ boric acid, $\mathrm{pH}$ 8.5. Sections were incubated in TBS $-0.1 \%$ Triton $\mathrm{X}-100-3 \%$ normal goat serum (TBS-Tds) for $30 \mathrm{~min}$ and with primary antibodies in TBSTds for $1-3 \mathrm{~d}$ at $4^{\circ} \mathrm{C}$. The primary antibody used for immunofluorescence staining were as follows: rat anti-BrdU, 1:100 (Herlan Sera Lab, Loughborough, UK); mouse anti- neuronal-specific nuclear protein (NeuN), 1:100 (Chemicon, Temecula, CA); rabbit anti $\mathrm{S} 100 \beta, 1: 2500$ (Swant, Bellinoza, Switzerland); rabbit anti-pCREB, 1:400 (New England Biolabs, Beverly, MA); and mouse anti-FLAG (1:500; Sigma). The fluorescent secondary antibodies used were anti-rat FITC, anti-rabbit Cy3, antimouse Cy3 or Cy5, 1:200 (Jackson ImmunoResearch, West Grove, PA).

Stereology. The number of BrdU-positive cells in the bilateral entire hippocampus region were counted with a coded one-in-nine series section for the rolipram study and a one-in-six series section the for transgenic mouse study. Using this approach, the number of sections analyzed to cover the entire hippocampus was 10 or 11 for the rolipram study and 15 or 16 for the transgenic mouse study. We used a modified version of the optical fractionator method for unbiased stereological analysis of the total number of BrdU-positive cells in the hippocampal subdivisions as reported previously (West et al., 1991) and as used and cited in a recent report (Gould et al., 1999). A cell was counted as being in the subgranular zone (SGZ) of the dentate gyrus if it was touching or in the SGZ. Cells that were located more than two cells away from the SGZ were classified as hilar. All BrdU-positive cells, regardless of size or shape, were counted through a $100 \times$ objective [Olympus BX-60 (Olympus Optical, Toyko, Japan) or Zeiss (Oberkochen, Germany)] throughout the rostrocaudal extent of the granule cell layer. The total numbers of BrdU-positive cells in both sides of granule cell layer or hilus were multiplied by 6 or 9 , respectively and reported as total number of cells per region.

Analysis of phenotypes. A one-in-nine series of sections from control $(n=6)$ and chronic rolipram-treated $(n=6)$ animals surviving 4 weeks after the injection of BrdU was triple labeled for BrdU, NeuN, and S100 $\beta$ as described above and analyzed by confocal laser microscopy (LSM 510; Zeiss). Fifty BrdU-positive cells per animal were analyzed for coexpression of BrdU and NeuN for neuronal phenotype and S100 $\beta$ for glial phenotype. Six chronic rolipram-treated and six control mice were analyzed. Ratios of BrdU-positive cells colabeling with NeuN, with S100 $\beta$, or with neither NeuN nor S100 $\beta$ were determined.

\section{RESULTS}

\section{Chronic rolipram administration increases the proliferation of granule cells in adult hippocampus}

The number of newly born cells in the adult dentate gyrus was determined by immunohistochemical detection of BrdU within the nuclei of dividing cells. Chronic or acute rolipram-treated and vehicle-treated control mice were killed $24 \mathrm{hr}$ after BrdU incorporation to detect proliferating cells (Fig. 1a,b). In chronic rolipram-treated animals, the number of BrdU-positive cells in the GCL was $6538 \pm 363$ (mean \pm SEM) cells per bilateral entire dentate gyri (BDG) compared with $4768 \pm 439$ cells per BDG in the controls, which corresponds to a $37 \%$ increase $(p<0.05)$ (Fig. 1a). In the hilus, the number of BrdU-positive cells was $601 \pm 32$ cells per BDG in rolipram-treated animals compared with $544 \pm 85$ cells per BDG in controls. In acute rolipramtreated animals, the number of BrdU-positive cells in GCL was 
a. Chronic rolipram (proliferation)

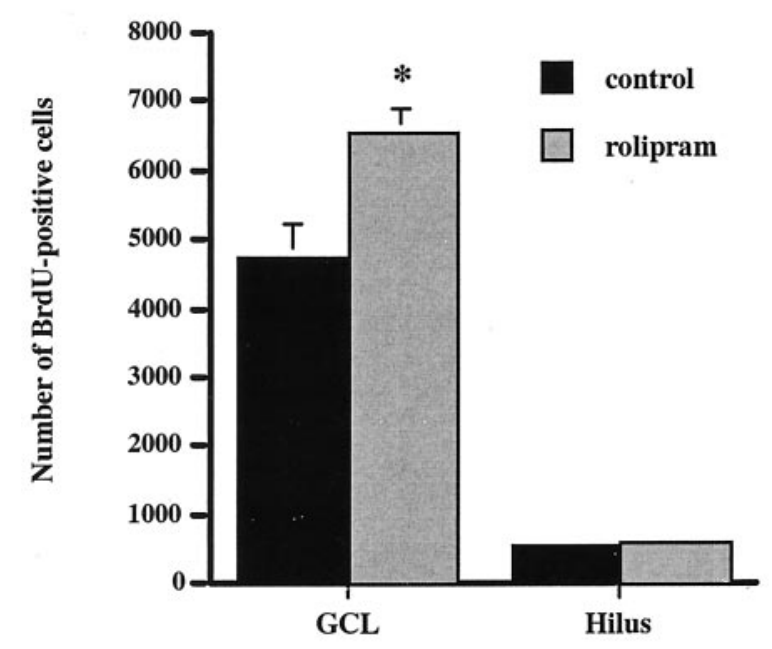

c. Chronic rolipram (proliferation, 2hr)

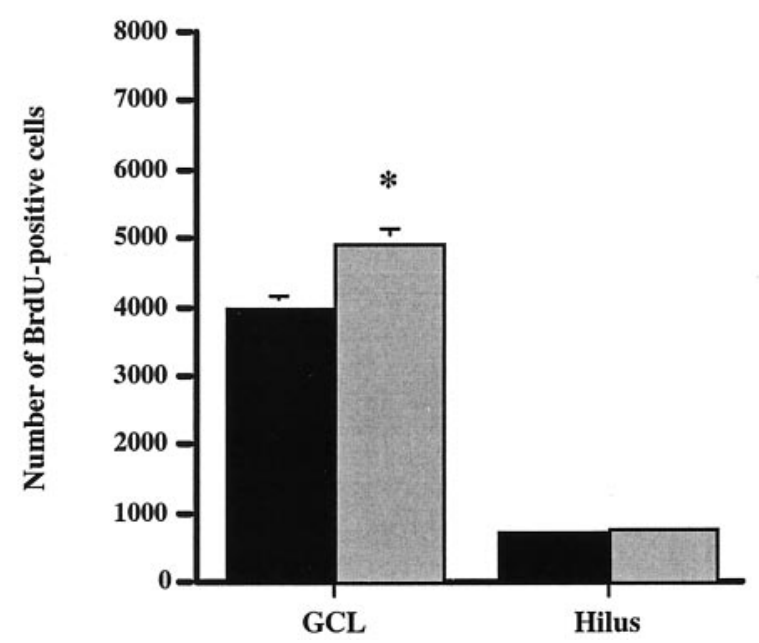

\section{b. Acute rolipram (proliferation)}

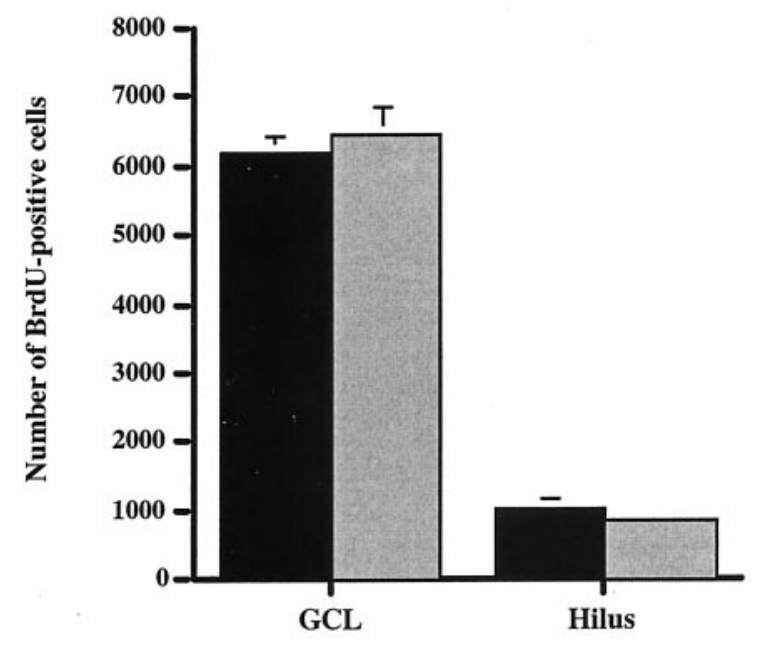

d. Chronic rolipram (survival)

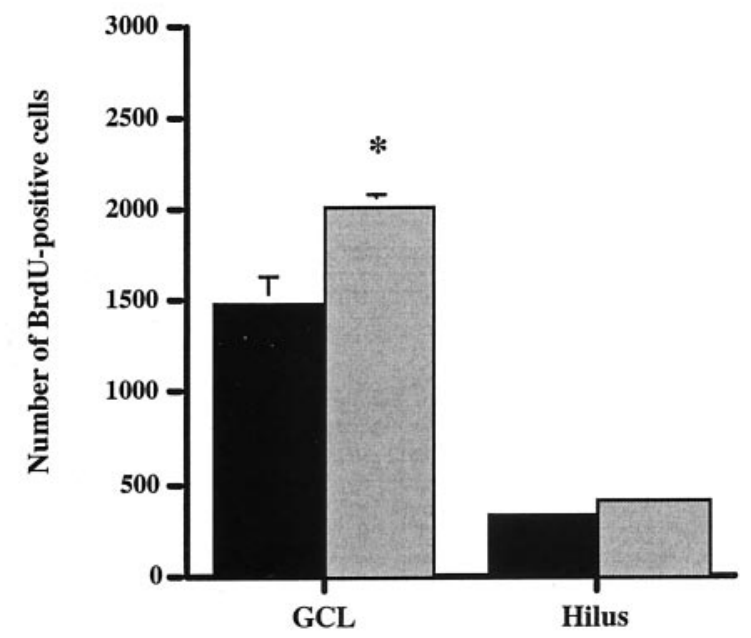

Figure 1. Effect of rolipram administration on cell proliferation in the adult hippocampus $(a-c)$. The number of BrdU-positive cells in the entire bilateral dentate gyri $24 \mathrm{hr}(a, b), 2 \mathrm{hr}(c)$, or 4 weeks $(d)$ after BrdU administration. Repeated (14 d) rolipram administration increased the number of proliferating cells in the granule cell layer compared with vehicle-treated control mice $(a, c)$. Acute $(1 \mathrm{~d})$ rolipram treatment had no effect on the number of newborn cells $(b)$. Chronic rolipram increased the number of surviving cells in the granule cell layer relative to control mice 4 weeks after BrdU administration $(d)$. The results are expressed as the mean \pm SEM number of BrdU-positive cells in bilateral dentate gyri $(n=6$ animals $)$. ${ }^{*} p<$ 0.05 compared with the corresponding control (Student's $t$ test).

$6442 \pm 394$ cells per BDG compared with $6210 \pm 209$ cells per BDG in controls (Fig. 1b). In the hilus, the number of BrdUpositive cells in acute rolipram-treated animals was $871 \pm 102$ cells per BDG compared with $1018 \pm 141$ cells per BDG in controls. These data indicate that chronic, but not acute, rolipram treatment results in more newborn cells in the dentate gyrus granule cell layer relative to control mice.

The length of $\mathrm{S}$ phase of the cell cycle at which BrdU is incorporated was estimated to be $\sim 8.0 \mathrm{hr}$ in the proliferating zone of adult hippocampus (Nowakowski et al., 1989). To confirm the results of chronic rolipram treatment on cell proliferation, a 2 hr time point after a single BrdU injection, which detects just a single round of dividing cells, was examined (Fig. 1c). In chronic rolipram-treated animals, the number of BrdU-positive cells in
GCL was $4902 \pm 244$ cells per BDG compared with $3994 \pm 160$ cells per BDG in controls, which corresponds to a $22 \%$ increase $(p<0.05)$. In the hilus, the number of BrdU-positive cells was $761 \pm 75$ per BDG in rolipram-treated animals compared with $753 \pm 104$ cells per BDG in controls.

BrdU-positive nuclei of proliferating cells were localized predominantly in the subgranular layer (the border between granule cell layer and hilus) or within GCL in both chronic rolipramtreated and control mice (Fig. 2a,b). The nuclei were darkly stained and exhibited variable shapes (Fig. $2 c, d$ ). In addition, the cells appeared frequently in clusters of two or more (Fig. $2 e$ ), and mitotic-like figures were observed in most sections (data not shown). This indicates that incorporation of BrdU occurs during proliferation of granule cells and cannot be explained by incor- 



Figure 2. Effect of chronic rolipram administration on the morphology and distribution of proliferating cells in the adult hippocampus. As quantified in Figure 1, chronic rolipram treatment $(b)$ increased the number of proliferating cells relative to control mice $(a)$. BrdU-positive cells were mostly in the subgranular layer between GCL and hilus $24 \mathrm{hr}$ after BrdU injection. $c-e$, Examples of proliferating cells $24 \mathrm{hr}$ after BrdU administration. Nuclei of BrdU-positive cells were dark and irregular in shape. Many proliferating cells occurred in clusters (arrow in $e$ ). No apparent difference in morphology and distribution of proliferating cells was seen between rolipram-treated and control mice. Scale bars: $a, b, 200 \mu \mathrm{m} ; c-e, 10 \mu \mathrm{m}$.

poration of the nucleotide during the repair of damaged DNA. The morphology of nuclei of newly generated cells was not different between rolipram-treated and control animals.

\section{Survival and phenotype of BrdU-labeled cells}

The number of $\left[{ }^{3} \mathrm{H}\right]$ thymidine-labeled newly born cells decreases during differentiation (Cameron et al., 1993). To determine whether the newborn cells observed after chronic rolipram treatment can survive, cells labeled with BrdU were allowed to mature for 4 weeks (Figs. 1d, 3). In chronic rolipram-treated animals, the number of BrdU-positive cells in GCL was $2012 \pm 74$ (mean \pm SEM) cells per BDG compared with $1491 \pm 145$ cells per BDG in controls, which corresponds to a $35 \%$ increase $(p<0.05)$ (Fig. $1 d)$. In the hilus, the number of BrdU-positive cells was $412 \pm 40$ cells per BDG in rolipram-treated animals compared with $324 \pm$ 24 cells per BDG in controls. Bright-field microscopic analysis shows that all BrdU-positive cells 4 weeks after BrdU administration are round and large with granular or dark-stained nuclei and are located within the GCL (Fig. $3 a, b$ ). BrdU-positive cells in rolipram-treated and control animals did not apparently differ in terms of their morphology and location.

To examine the phenotype of mature BrdU-positive cells in the GCL, triple labeling for BrdU, the mature neuronal marker NeuN (Mullen et al., 1992), and the glial marker S100 $\beta$ (Boyes et al., 1986) was performed (Figs. $3 c-j, 4)$. Confocal microscopic analysis showed that the majority of BrdU-positive cells colocalized with NeuN [79.3 \pm 3.2 and $76.3 \pm 3.2 \%$ for control and chronic rolipram-treated animals, respectively (mean \pm SEM)], and a much smaller percentage colocalized with $\mathrm{S} 100 \beta[5.6 \pm 1.0$ and $8.3 \pm 0.9 \%$ for control and chronic rolipram-treated animals, respectively (mean $\pm \mathrm{SEM})]$. The percentage of cells that mature into neurons or glia was not different in vehicle- and rolipramtreated groups (Fig. 3k).

\section{Rolipram increases the phosphorylation of CREB in the granule cell layer of hippocampus}

Rolipram is a specific inhibitor of the high-affinity cAMP phosphodiesterase IV, which can activate the cAMP system by inhibiting cAMP breakdown, and could result in increased phosphorylation of CREB (Conti and Jin, 2000). To examine the phosphorylation of CREB in adult dentate GCL with acute or chronic rolipram treatment, immunofluorescence staining with antibodies against phosphorylated CREB (pCREB) was performed (Fig. $4 a-d$ ). In animals with acute or chronic saline treatment, the pCREB immunohistochemistry was observed in nuclei of cells aligned in the lowest part of GCL, adjacent to or including the SGZ, of adult dentate gyrus (Fig. 4a,c). Although a similar staining pattern was seen in the acute rolipram-treated animals (Fig. 4b), chronic rolipram treatment increased pCREB immunostaining in whole GCL, including the subgranular zone, as well as CA4 and hilus region (Fig. $4 d$ ). This magnitude of pCREB labeling was observed in $\sim 70 \%$ of the animals that received chronic rolipram treatment. In the remaining $30 \%$ of the animals tested, pCREB was still increased relative to vehicle or acute rolipram treatment but in a smaller portion of the GCL. There was no difference in the rostrocaudal extent of the staining pattern.

To determine the relationship between newly born cells and pCREB-expressing cells in the subgranular zone of the GCL, brain sections from acute or chronic rolipram-treated animals killed $24 \mathrm{hr}$ after BrdU injection were double stained with antibodies against BrdU and pCREB (Fig. $4 e-j$ ). Similar results were found $2 \mathrm{hr}$ after injection of BrdU. BrdU-positive newborn cells were localized in the subgranular layer but did not colocalize with pCREB-expressing cells in either the acute (Fig. 4e-g) or chronic (Fig. $4 h-j$ ) rolipram-treated animals. Together, these findings 

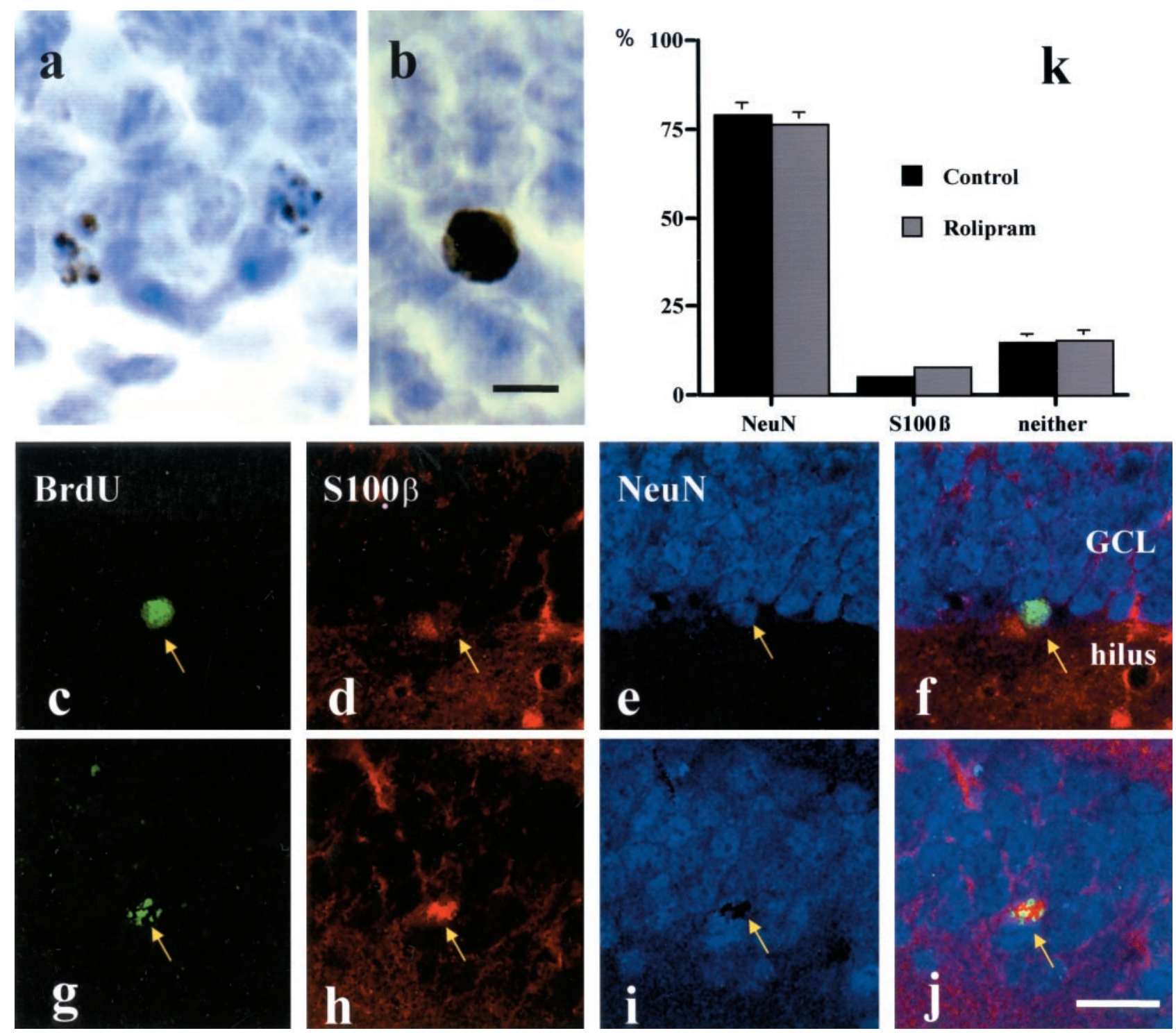

Figure 3. Effect of chronic rolipram administration on the morphology, distribution, and phenotype of surviving cells in the adult hippocampus. BrdU-positive cells 4 weeks after BrdU administration showed mature cell morphology within the GCL: sparse, multipunctate $(a)$ or dark, uniform $(b)$ BrdU-labeled nuclei with pale cytoplasm. Confocal images of triple-labeled cells with the mitotic marker BrdU ( green; $c, g)$, the glial marker S100 $\beta$ (red; $d, h)$, the neuronal marker NeuN (blue; $e, i)$, and merged images of the three labels $(f, j)$ demonstrate cells with a neuronal $(c-f)$ or glial $(g-j)$ phenotype. Scale bars: $a, b, 10 \mu \mathrm{m} ; c-j, 20 \mu \mathrm{m}$. Rolipram-treated and control mice did not differ in depth and morphology of BrdU-positive cells within the granule cell layer. The number of BrdU-labeled cells expressing either NeuN or $\mathrm{S} 100 \beta$ was determined for each group. The results are expressed as percentage and are the mean \pm SEM of a total of 50 cells counted for each group. There was no significant difference between the control and chronic rolipram-treated mice.

demonstrate that pCREB immunohistochemistry is induced by chronic rolipram administration in granule cells throughout the GCL but not in newborn BrdU-labeled cells.

\section{Overexpression of a dominant negative mutant of CREB (mCREB) decreases granule cell proliferation}

To assess the role of CREB phosphorylation in adult hippocampal neurogenesis, we used transgenic mice with inducible, regionspecific expression of a FLAG-tagged dominant negative CREB (mCREB) by means of crossbreeding CaMKII-tTA mice (Mayford et al., 1996) with mice containing the TetOP-mCREB gene (Fig. 5). CaMKII-tTA and TetOP-mCREB single transgenic mice and CaMKII-tTA $\times$ TetOP-mCREB bitransgenic mice were bred with doxycycline in the drinking water from conception to postnatal week 6 , followed by a 4 week period without doxy- cycline. All three genotypes displayed normal voluntary movement and activity during development and approximately the same body weight at postnatal week 10 (CaMKII-tTA mice, $24.7 \pm 0.3 \mathrm{gm}, n=4$; TetOP mCREB mice, $25.1 \pm 0.7 \mathrm{gm}, n=$ 7; CaMKII-tTA $\times$ TetOP-mCREB mice, $24.1 \pm 1.1 \mathrm{gm}, n=5$ ).

The expression of the FLAG-tagged mCREB was visualized by immunohistochemistry using an anti-FLAG antibody. At postnatal week 6 with doxycycline in the drinking water, both single transgenic and bitransgenic mice showed no FLAG immunoreactivity (data not shown). This finding indicates that the dosage of doxycycline $(100 \mu \mathrm{g} / \mathrm{ml}$ in drinking water) used was sufficient to turn off the expression of mCREB. At postnatal week 10, after 4 weeks off doxycycline, strong expression of FLAG was seen in several forebrain regions of CaMKII-tTA $\times$ TetOP-mCREB 

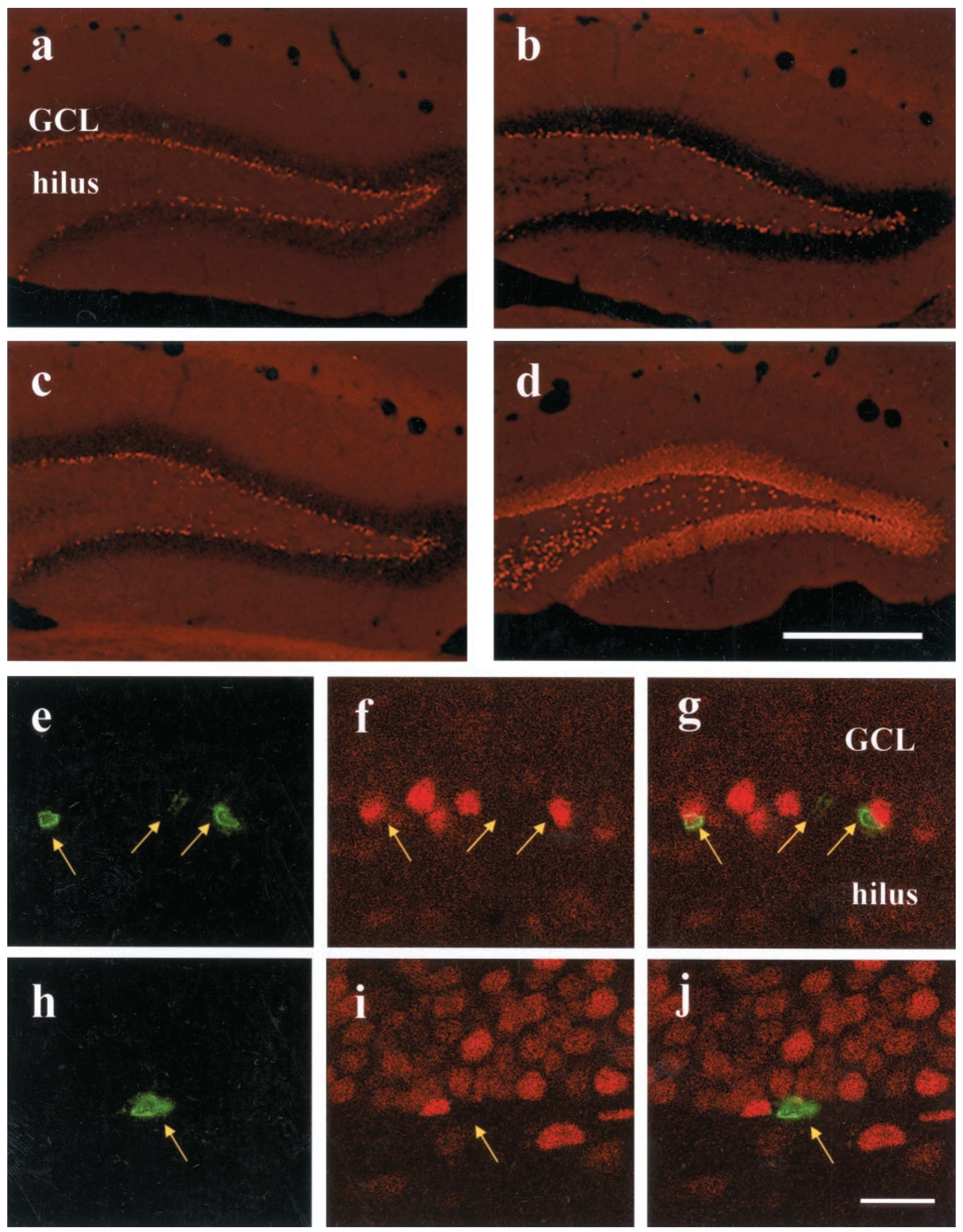

Figure 4. $a-d$, Immunostaining of pCREB in the adult dentate gyrus of acute or chronic rolipram-treated mice. Confocal images with low magnification showed that pCREB-immunopositive cells were aligned in the deepest part of GCL in the control animals $(a, c)$. Although the same immunostaining pattern was seen in the acute rolipram-treated mice $(b)$, the entire granule cell layer was strongly stained with pCREB antibody in the chronic rolipram-treated mice $(d) \cdot e-j$, Double immunolabeling of BrdU (green) and pCREB (red) in the adult dentate gyrus of chronic rolipram-treated mice $24 \mathrm{hr}$ after BrdU administration. Confocal images with high magnification showed that BrdU-labeled cells (arrows) did not show immunoreactivity of pCREB in either acute $(e-g)$ or chronic $(h-j)$ rolipram-treated animals. Scale bars: $a-d, 200 \mu \mathrm{m} ; e-j, 20 \mu \mathrm{m}$. 


\section{Gene 1 (CaMKII-tTA)}

CaMKII promoter

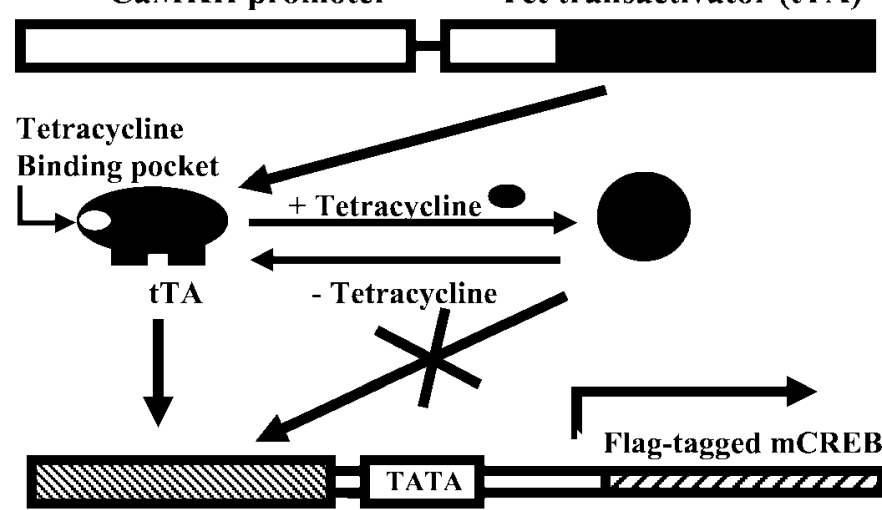

TetOP promoter which needs

bound tTA to drive transeription

\section{Gene 2 (TetOP-mCREB)}

Figure 5. Schematic diagram of the tetracycline-regulated gene expression system. Gene 1 encodes the tetracycline-regulated transactivator protein tTA under the control of CaMKII $\alpha$ promoter. Gene 2 encodes the FLAG-tagged CREB mutant (mCREB) gene with modified phosphorylation site ( $\mathrm{Ser}^{133}$ to Ala) under the control of the tetracycline-responsive promoter TetOP. In the absence of doxycycline, a tetracycline analog, tTA binds to and activates TetOP and increases the expression of the downstream target gene mCREB. When doxycycline is added, it binds to tTA, causes a conformational change of tTA, and prevents it from activating TetOP, thereby turning off the expression of target genes. We used transgenic mice that received doxycycline in the drinking water during development (i.e., pregnant mothers received doxycylcine) to postnatal week 6 , followed by 4 weeks without doxycycline.

bitransgenic mice, including olfactory bulb, superficial and deep layers of cortex, caudate putamen, nucleus accumbens, amygdala, hippocampus, and Purkinje cells of the cerebellar lobule X (Fig. $6 a-d)$. FLAG-mCREB staining was not observed in the thalamus, midbrain, or medulla oblongata (Fig. 6a,b). Bright-field microscopic images with higher magnification showed that most of, but not all, granule cells in hippocampal dentate gyrus expressed mCREB (Fig. 6d,e). This expression pattern was very similar to that seen for the first line of CaMKII $\alpha$ promoter-tTA transgenic mice described by Kandel and his colleagues (Mayford et al., 1996). In contrast, no immunoreactivity was observed in CaMKII-tTA (data not shown) or TetOP-mCREB (Fig. 6c) single transgenic mice. These findings demonstrate that the expression of mCREB was regulated by doxycycline in a timelimited and region-specific manner.

Both single transgenic and bitransgenic mice at postnatal week 10 were killed $2 \mathrm{hr}$ after a single injection of $\mathrm{BrdU}$, and the proliferation of newborn cells was determined by immunodetection of BrdU. In the GCL of the CaMKII-tTA and TetOPmCREB single transgenic lines, the numbers of BrdU-positive cells were $3904 \pm 581$ and $3729 \pm 97$ cells per BDG, respectively (Fig. $6 g$ ). However, there was a significant decrease in the number of BrdU-positive cells in the GCL of the CaMKII-tTA $\times$ TetOPmCREB bitransgenic mice $(2462 \pm 280$ cells per BDG; $p<0.05)$. There was no difference in the number of BrdU-positive cells in the hilus region among the three groups. The morphology and distribution of BrdU-positive cells in the dentate gyrus of the three transgenic lines tested did not differ from that in the wild-type mice (data not shown). This demonstrates that there are no gross abnormalities that preclude the use of these condi- tional lines of mCREB mice for these studies. Finally, newborn BrdU-labeled cells were not colocalized with mCREBimmunopositive cells in the bitransgenic mice, although the BrdU-labeled cells were surrounded by mCREB-stained cells (Fig. 6f).

\section{DISCUSSION}

The results of both pharmacological and conditional transgenic approaches used for this study demonstrate that activation of the cAMP-CREB cascade increases the number of BrdU-labeled cells in the hippocampus. Chronic, but not acute, administration of rolipram increases the number of BrdU-labeled cells in the granule cell layer. The requirement for repeated treatment is somewhat unexpected because rolipram should increase cAMP within a relatively short period of time (i.e., minutes to hours after reaching the brain). However, the increase in cAMP levels is dependent not only on the rate of degradation but also on the rate of synthesis. It is possible that synthesis is not sufficiently high to support a significant increase of cAMP levels, even in the presence of the PDE4 inhibitor. This is supported by studies in brain slices that demonstrate a relatively small effect of rolipram on basal cAMP levels but a much greater increase in the presence of forskolin, an activator of cAMP synthesis (Barad et al., 1998). However, it is important to point out that the exact status of cAMP accumulation in hippocampal cells is not known and that there may be an alternate explanation for the requirement for chronic rolipram administration. One possibility is that the induction of proliferation is dependent on long-term adaptations that occur in response to repeated rolipram treatment. A similar scenario is proposed for antidepressants, which acutely increase monoamine levels but require repeated administration to induce hippocampal proliferation (Malberg et al., 2000a). For example, chronic antidepressant administration upregulates the cAMP cascade, including increased expression of CREB (Nibuya et al., 1996; Duman et al., 1997b, 2000). Yet another possibility is that rolipram is acting indirectly via regulation of factors or endocrine systems in other parts of the brain or even in other tissues that then lead to regulation of neurogenesis in hippocampus. For example, peripheral regulation of insulin-like growth factor-1 (IGF-1) is reported to increase neurogenesis in adult hippocampus (Aberg et al., 2000).

The influence of rolipram treatment on the fate of newborn cells was examined 4 weeks after BrdU administration. Because many newborn cells do not survive, the total number of BrdUlabeled cells in control and rolipram-treated hippocampus decreases proportionally at this time point, as reported previously (Gould et al., 1999). However, there is still a significant increase in the number of BrdU-labeled cells in rolipram-treated animals relative to controls. At this later time, $\sim 80 \%$ of the cells express a neuronal marker (NeuN), and $5-10 \%$ express a glial marker (S100 $\beta$ ), as reported previously (van Praag et al., 1999). The cells expressing NeuN have migrated into the granule cell layer and have characteristics of mature granule cells. The percentage of cells expressing these markers was not significantly influenced by rolipram treatment. These results demonstrate that the newborn cells resulting from the rolipram treatment have a cellular phenotype that is the similar to that of vehicle-treated controls but that the net number of BrdU-labeled neurons is significantly increased by chronic rolipram administration. It should also be pointed out that the survival of newborn cells at even longer time points could be different from that observed in the present study because a recent report demonstrates that there is a further loss 

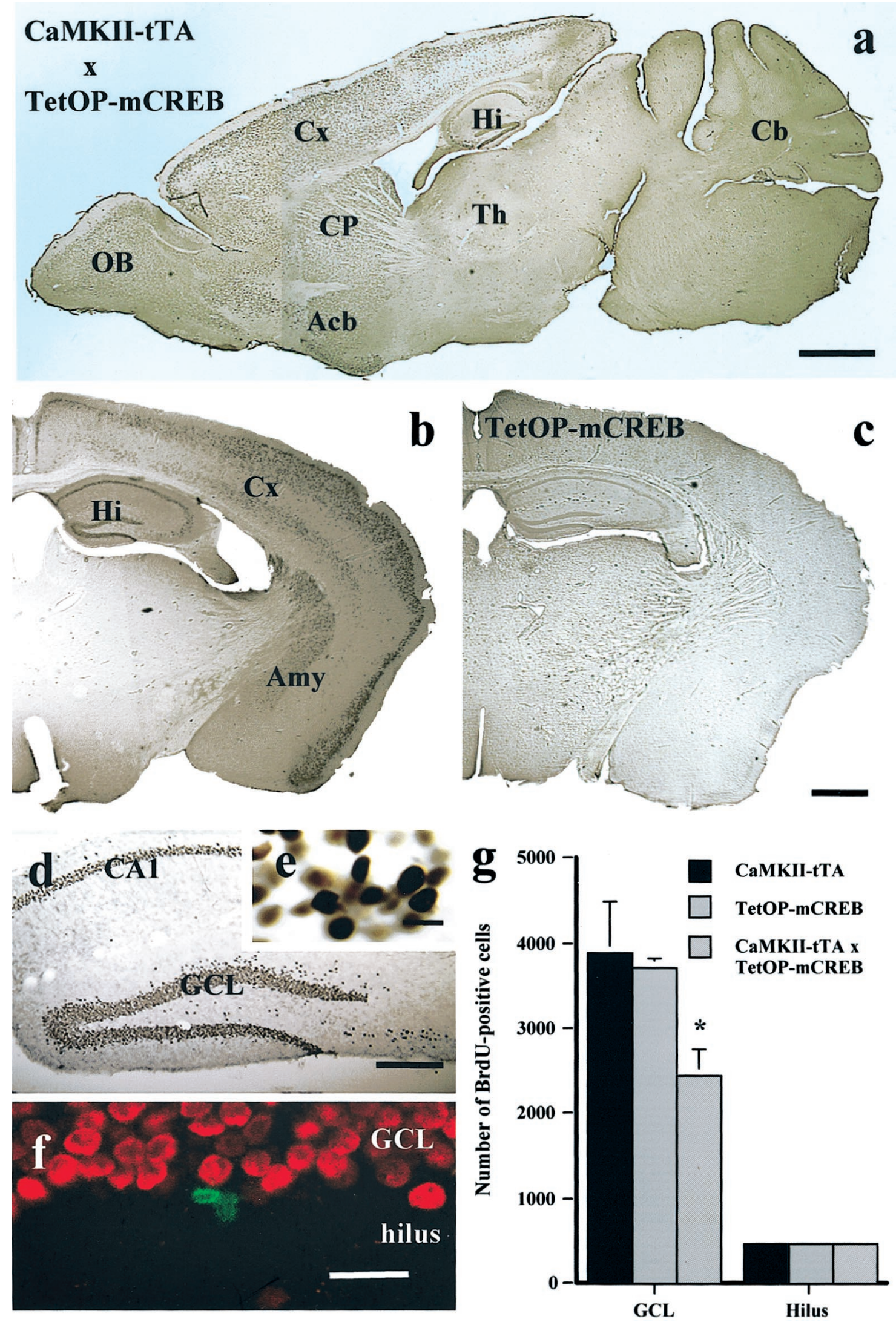

Figure 6. Inducible expression of mCREB decreases cell proliferation in hippocampus. mCREB expression was detected in olfactory bulb $(O B)$, cortex $(C x)$, piriform cortex (Pir), caudate putamen $(C P)$, nucleus accumbens $(A c b)$, amygdala $(A m y)$, hippocampus $(H i)$, and cerebellum $(C b)$ but not in the thalamus $(T h)$ and midbrain and medulla oblongata $(a, b)$ in CaMKII-tTA $\times$ TetOP-mCREB bitransgenic mice. No immunoreactivity was shown in TetOP-mCREB single transgenic mice $(c)$. In the dentate gyrus, most of, but not all, granule cells $(d)$ and a few cells in (Figure legend continues.) 
of BrdU-labeled cells 5-9 weeks after BrdU administration in monkeys (Gould et al., 2001).

CREB regulates gene expression in response to activation of the cAMP system (Duman et al., 2000) and could contribute to the observed upregulation of cell proliferation. One striking finding of this study is that there is marked localization of pCREB immunoreactivity in the subgranular zone, suggesting a possible relationship with cell proliferation. Chronic, but not acute, administration of rolipram increases the number of pCREBimmunopositive cells throughout the granule cell layer, including cells adjacent to the subgranular zone. This is consistent with the time course for the induction of cell proliferation by repeated, but not acute, rolipram administration. Double-labeling studies confirm that pCREB staining is localized to the subgranular zone but also demonstrate that pCREB is not colocalized with newborn BrdU-labeled cells. There are two possible interpretations of these results. First, rolipram may not directly influence the cAMP-CREB cascade in the progenitor cells but influences surrounding cells that then increase proliferation via release of a factor that increases proliferation. The second possibility is that rolipram does influence the progenitor cells but that this effect is transient and occurs during a brief time interval preceding and/or shortly after cell division.

The role of CREB in regulation of cell proliferation was directly examined using conditional transgenic mice that over express a dominant negative CREB mutant. The CaMKII promoter was used to drive expression of tTA and subsequent regulation of TetOp-mCREB and was shown to be sensitive to inhibition by doxycycline. The pattern of $\mathrm{mCREB}$ expression was similar to that reported previously in mice using this same line of CaMKII-tTA mice crossed with another TetOp-regulated transgene (Mayford et al., 1996). This distribution includes robust expression in the granule cell layer of hippocampus. When mCREB was overexpressed, there was a significant reduction in the number of BrdU-labeled cells. This is consistent with the hypothesis that the $\mathrm{CAMP}-\mathrm{CREB}$ cascade exerts a positive influence on proliferation in adult hippocampus.

Because the CaMKII promoter is turned on during late embryonic or early postnatal development, the expression of mCREB is not expected to occur in progenitor cells or newborn cells. This was confirmed by double-labeling studies. Expression of mCREB is found in most granule cells in the dentate gyrus but not in newborn cells that are immunopositive for BrdU. The localization of mCREB in cells that surround, but not in, the BrdU-labeled cells is consistent with the hypothesis that the cAMP-CREB cascade regulates cell proliferation indirectly via expression of a factor(s) that is released from granule cells that surround progenitor cells. Some of the factors that are reported to increase cell proliferation during development or in adult brain and that could mediate the effect of the cAMP system include IGF-1, epidermal growth factor, transforming growth factor- $\alpha$, and fibroblast growth factor-2 (Cameron et al., 1998).

Another aspect of neurogenesis that could be influenced by the
cAMP-CREB cascade is the maturation and survival of newborn cells. The experimental design to directly examine survival is to label newborn cells with BrdU and then administer rolipram for 4 weeks during the time when cells are maturing and when there is natural cell death. Preliminary studies using this paradigm demonstrate that rolipram treatment also influences the survival of cells (Nakagawa et al., 2000). In addition, we found that pCREB immunoreactivity is colocalized with, and may regulate the expression of, markers of immature neurons in the BrdUlabeled cells (Nakagawa et al., 2000). Further characterization of the actions of the CAMP-CREB cascade on cell survival and the factors that mediate these effects warrant an independent and in depth series of experiments and is the focus of current investigations.

The cAMP-CREB cascade could underlie the action of different neurotransmitters, neurotrophic factors, or conditions known to influence neurogenesis. One possibility is learning and memory, which is known to be influenced by activation of cAMPCREB cascade and associated with increased CREB phosphorylation in the hippocampus (Barad et al., 1998; Silva et al., 1998). Hippocampal-dependent learning is also reported to increase neurogenesis (Gould et al., 1999). Although the time course for the regulation of learning and memory in both cellular and behavioral models occurs in a much shorter time frame, it is possible that upregulation of cell proliferation enhances the maintenance or processing of memories.

The results of this study may also have relevance to our understanding of the action of antidepressants. Previous studies demonstrate that repeated antidepressant treatment upregulates the cAMP-CREB pathway (Nibuya et al., 1996; Thome et al., 2000), suggesting that this second-messenger cascade may be involved in the actions of antidepressant treatment (Duman et al., 1997b, 2000). In addition, repeated antidepressant treatment increases hippocampal granule cell proliferation (Malberg et al., 2000a). Rolipram is also reported to have antidepressant effects in animal models of depression and has been shown to have efficacy in depressed patients (Duman et al., 1997b, 2000). Together, the results are consistent with the hypothesis that upregulation of the cAMP pathway underlies the induction of granule cell proliferation in response to antidepressant treatment. Although it is difficult to extrapolate from these findings to studies in humans, it is interesting to speculate that the induction of hippocampal proliferation could block or reverse the atrophy of hippocampus reported in clinical studies (Duman et al., 1997b, 2000). Additional brain imaging and postmortem studies will be needed to determine whether there is a decrease in the number of granule cells in the hippocampus of unmedicated depressed patients and whether hippocampal atrophy and cell loss is reversed by antidepressant treatment.

\section{REFERENCES}

Aberg M, Aberg ND, Hedbacker H, Oscarsson J, Eriksson PS (2000) Peripheral infusion of IGF-1 selectively induces neurogenesis in the adult rat hippocampus. J Neurosci 20:2896-2903.

(Figure legend continued.) the CA3 region expressed mCREB $(d)$. Double immunolabeling for BrdU and mCREB in the adult hippocampus of bitransgenic mice $2 \mathrm{hr}$ after BrdU administration is shown in $f$. There was no mCREB immunoreactivity in the BrdU-positive cells. Scale bars: $a$, 1 mm; $b-d, 200 \mu \mathrm{m} ; e, f, 20 \mu \mathrm{m}$. Mice expressing mCREB in the hippocampus or genotype controls were treated with BrdU and 2 hr later harvested for immunohistochemical analysis. The number of proliferating cells in the granule cell layer was significantly decreased in the bitransgenic mice relative to single transgenic mice $(g)$. CaMKII-tTA, CaMKII-tTA single transgenic mice with no mCREB expression; TetOP-mCREB, TetOP-mCREB single transgenic mice with no mCREB expression; CaMKII-tTA $\times$ TetOP-mCREB, CaMKII-tTA $\times$ TetOP-mCREB bitransgenic mice that express mCREB in hippocampus. ${ }^{*} p<0.05$ compared with the single transgenic control (ANOVA, followed by Scheffe's post hoc comparison). 
Barad M, Bourtchouladze R, Winder DG, Golan H, Kandel E (1998) Rolipram, a type IV-specific phosphodiesterase inhibitor, facilitates the establishment of long-lasting long-term potentiation and improves memory. Proc Natl Acad Sci USA 95:15020-15025.

Boyes B, Kim SU, Lee V, Sung SC (1986) Immunohistochemical colocalization of S-100b and the glial fibrillary acidic protein in rat brain. Neuroscience 17:857-865.

Cameron H, McKay RDG (1999) Restoring production of hippocampal neurons in old age. Nat Neurosci 2:894-897.

Cameron H, Wooley CS, McEwen BS, Gould E (1993) Differentiation of newly boron neurons and glia in the dentate gyrus of the adult rat. J Neurosci 56:337-344.

Cameron H, Hazel TG, McKay RD (1998) Regulation of neurogenesis by growth factors and neurotransmitters. J Neurobiol 36:287-306.

Chen J, Kelz MB, Zeng G, Sakai N, Steffen C, Shockett PE, Picciotto MR, Duman RS, Nestler EJ (1998) Transgenic animal models with inducible, targeted gene expression in brain. Mol Pharmacol 54:495-503.

Conti M, Jin S-L (2000) The molecular biology of cyclic nucleotide phosphodiesterases. Prog Nucleic Acid Res Mol Biol 63:1-38.

Duman R, Heninger GR, Nestler EJ (1997) A molecular and cellular theory of depression. Arch Gen Psychiatry 54:597-606.

Duman R, Malberg J, Nakagawa S, D’Sa C (2000) Neuronal plasticity and survival in mood disorders. Biol Psychiatry 48:732-739.

Eriksson P, Perfileva E, Bjork-Eriksson T, Alborn A, Nordborg C, Peterson D, Gage F (1998) Neurogenesis in the adult human hippocampus. Nat Med 4:1313-1317.

Finkbeiner S (2000) CREB couples neurotrophin signals to survival messages. Neuron 25:11-14.

Furth P, Onge LS, Böger H, Gruss P, Gossen M, Kistner A, Bujard H, Hennighausen L (1994) Temporal control of gene expression in transgenic mice by a tetracycline-responsive promoter. Proc Natl Acad Sci USA 91:9302-9306.

Gage F (2000) Mammalian neural stem cells. Science 287:1433-1438.

Gonzalez G, Montminy MR (1989) Cyclic AMP stimulates somatostatin gene transcription by phosphorylation of CREB at serine 133. Cell 59:675-680.

Gould E, McEwen BS, Tanapat P, Galea LAM, Fuchs E (1997) Neurogenesis in the dentate gyrus of the adult tree shrew is regulated by psychosocial stress and NMDA receptor activation. J Neurosci 17:2492-2498.

Gould E, Beylin A, Tanapat P, Reeves A, Shors TJ (1999) Learning enhances adult neurogenesis in the hippocampal formation. Nat Neurosci 2:260-265.

Gould E, Vail N, Wagers M, Gross CG (2001) Adult-generated hippocampal and neocortical neurons in macaques have a transient existence. Proc Natl Acad Sci USA 98:10910-10917.

Kempermann G, Kuhn HG, Gage F (1997) More hippocampal neurons in adult mice living in an enriched environment. Nature 386:493-495.

Kuhn H, Dickinson-Anson H, Gage FH (1996) Neurogenesis in the dentate gyrus of the adult rat: age-related decrease of neuronal progenitor proliferation. J Neurosci 16:2027-2033.

Kukekov V, Laywell ED, Suslov O, Davies K, Scheffler B, Thomas LB, O'Brien TF, Kusakabe M, Steindler DA (1999) Multipotent stem/ progenitor cells with similar properties arise from two neurogenic regions of adult human brain. Exp Neurol 156:333-344.
Malberg J, Eisch AJ, Nestler EJ, RS Duman (2000a) Chronic antidepressant treatment increases neurogenesis in adult hippocampus. J Neurosci 20:9104-9110.

Mayford M, Bach ME, Huang YY, Wang L, Hawkins RD, Kandel ER (1996) Control of memory formation through regulated expression of a CaMKII transgene. Science 274:1678-1683.

Mullen R, Buck CR, Smith AM (1992) NeuN, a neuronal specific nuclear protein in vertebrates. Development 116:201-211.

Nakagawa S, Kim J-E, Lee R, Chen J, Duman RS (2000) CREB plays a critical role in the survival of newborn cells in the adult hippocampus. Soc Neurosci Abstr 26:2317.

Nibuya M, Nestler EJ, Duman RS (1996) Chronic antidepressant administration increases the expression of cAMP response element binding protein (CREB) in rat hippocampus. J Neurosci 16:2365-2372.

Nowakowski R, Lewin SB, Miller MW (1989) Bromodeoxyuridine immunohistochemical determination of the lengths of the cell cycle and the DNA-synthetic phase for an anatomically defined population. J Neurocytol 18:311-318.

Palmer T, Takahashi J, Gage FH (1997) The adult rat hippocampus contains primordial neural stem cells. Mol Cell Neurosci 8:389-404.

Pincus D, Keyoung HM, Harrison-Restelli C, Goodman RR, Fraser RA, Edgar M, Sakakibara S-I, Okano H, Nedergaard M, Goldman SA (1998) Fibroblast growth factor-2/brain-derived neurotrophic factorassociated maturation of new neurons generated from adult human subependymal cells. Ann Neurol 43:576-585.

Shaywitz A, Greenberg ME (1999) CREB: a stimulus-induced transcription factor activated by a diverse array of extracellular signals. Annu Rev Biochem 68:821-861.

Sheline Y, Wany P, Gado MH, Csernansky JG, Vannier MW (1996) Hippocampal atrophy in recurrent major depression. Proc Natl Acad Sci USA 93:3908-3913.

Shockett P, Difilippantonio M, Hellman N, Schatz DG (1995) A modified tetracycline-regulated system provides autoregulatory, inducible gene expression in cultured cells and transgenic mice. Proc Natl Acad Sci USA 6522-6526.

Silva A, Kogan JH, Frankland PW, Kida S (1998) CREB and memory. Annu Rev Neurosci 21:127-148.

Steffens D, Byrum CE, McQuoid DR, Greenberg DL, Payne ME, Blitchington TF, MacFall JR, Krishnan KRR (2000) Hippocampal volume in geriatric depression. Biol Psychiatry 48:301-309.

Takahashi J, Palmer TD, Gage FH (1998) Retinoic acid and neurotrophins collaborate to regulate neurogenesis in adult-derived neural cell cultures. J Neurobiol 38:65-81.

Thome J, Sakai N, Shin K, Steffen C, Zhang YJ, Impey S, Storm D, Duman RS (2000) cAMP response element-mediated gene transcription is upregulated by chronic antidepressant treatment. J Neurosci 20:4030-4036.

van Praag H, Kempermann G, Gage FH (1999) Running increases cell proliferation and neurogenesis in the adult mouse dentate gyrus. Nat Neurosci 2:266-270.

van Praag H, Kempermann G, Gage FH (2000) Neural consequences of environmental enrichment. Nat Rev Neurosci 1:191-198.

West M, Slomianka L, Gundersen H (1991) Unbiased stereological estimation of the total number of neurons in the subdivision of the rat hippocampus using the optical fractionator. Anat Rec 231:482-497. 